\title{
EFFECT OF TRANSVERSE SURFACE ROUGHNESS ON THE PERFORMANCE OF HYDROMAGNETIC SQUEEZE FILM BETWEEN CONDUCTING TRUNCATED CONICAL PLATES
}

\author{
Pragna Amratlal Vadher \\ Department of Physics, Government Science College, Gandhinagar - 382016 Gujarat State, India. \\ Gunamani Deheri \\ Department of Mathematics, Sardar Patel University, Vallabh Vidyanagar - 388 120, Gujarat State, India. \\ Rakesh Manilal Patel \\ Department of Mathematics, Gujarat Arts and Science College, Ahmedabad - 380006 Gujarat State, India., \\ jrmpatel@rediffmail.com
}

Follow this and additional works at: https://jmstt.ntou.edu.tw/journal

Part of the Engineering Commons

\footnotetext{
Recommended Citation

Vadher, Pragna Amratlal; Deheri, Gunamani; and Patel, Rakesh Manilal (2011) "EFFECT OF TRANSVERSE SURFACE ROUGHNESS ON THE PERFORMANCE OF HYDROMAGNETIC SQUEEZE FILM BETWEEN CONDUCTING TRUNCATED CONICAL PLATES," Journal of Marine Science and Technology. Vol. 19: Iss. 6, Article 12.

DOI: $10.51400 / 2709-6998.2210$

Available at: https://jmstt.ntou.edu.tw/journal/vol19/iss6/12

This Research Article is brought to you for free and open access by Journal of Marine Science and Technology. It has been accepted for inclusion in Journal of Marine Science and Technology by an authorized editor of Journal of Marine Science and Technology.
} 


\section{EFFECT OF TRANSVERSE SURFACE ROUGHNESS ON THE PERFORMANCE OF HYDROMAGNETIC SQUEEZE FILM BETWEEN CONDUCTING TRUNCATED CONICAL PLATES}

\section{Acknowledgements}

Authors place on record sincere thanks to the referees for their constructive suggestions, and comments towards the presentation of the paper in a fruitful way. Two of the authors, R. M. Patel and G. M. Deheri thank UGC for the funding of U. G. C. major research project (U. G. C. F. No. 32-143/2006 (SR) - "Magnetic fluid based rough bearings") under which this study has been carried out. 


\title{
EFFECT OF TRANSVERSE SURFACE ROUGHNESS ON THE PERFORMANCE OF HYDROMAGNETIC SQUEEZE FILM BETWEEN CONDUCTING TRUNCATED CONICAL PLATES
}

\author{
Pragna Amratlal Vadher*, Gunamani Deheri**, and Rakesh Manilal Patel***
}

Key words: hydromagnetic squeeze film, transverse surface roughness, Reynolds' equation and load carrying capacity.

\begin{abstract}
An attempt has been made to study and analyze the behavior of a hydromagnetic squeeze film between conducting porous transversely rough truncated conical plates. The associated Reynolds' equation is solved with appropriate boundary conditions to investigate the behavior of performance characteristics. The results indicate that the performance of the bearing system gets enhanced vis-à-vis a bearing system working with a conventional lubricant. This article reveals that the negative effect induced by porosity and standard deviation can be overcome completely by the positive effect of the magnetization parameter and conductivities by choosing suitable aspect ratio and the semi-vertical angle in the case of negatively skewed roughness.
\end{abstract}

\section{INTRODUCTION}

Owing to the large electrical conductivity of liquid metals such as mercury, sodium, the possibilities of electromagnetic pressurization from the application of an external magnetic field, have been explored and investigated. This electromagnetic pressurization comes into force when a large external electromagnetic field through the electrically conducting lubricant is applied to induce circulating currents which in turn, interacts with the magnetic field to create a body force which

\footnotetext{
Paper submitted 12/30/09; revised 03/08/10; accepted 07/14/10. Author for correspondence: Rakesh Manilal Patel (e-mail: jrmpatel@rediffmail.com). *Department of Physics, Government Science College, Gandhinagar - 382016 Gujarat State, India.

**Department of Mathematics, Sardar Patel University, Vallabh Vidyanagar - 388 120, Gujarat State, India.

***Department of Mathematics, Gujarat Arts and Science College, Ahmedabad -380 006 Gujarat State, India.
}

pumps the fluid between the bearing surfaces. Since the liquid metals are good electrical conductors it becomes possible to increase the load carrying capacity by making use of electromagnetic force and thereby, overcoming the defect associated with lubricants at higher temperature and thus alleviating the drawbacks of low viscosity.

A number of investigators have conducted theoretical and experimental studies on the hydromagnetic lubrication of porous as well as plane metal bearings (Elco and Huges [8], Kuzma [11], Kuzma et al. [12], Dodge et al. [7]). Shukla [18] dealt with the hydromagnetic squeeze film bearing for conducting lubricants between non conducting non-porous surfaces in the presence of a transverse magnetic field. Shukla and Prasad [19] discussed the performance of a hydromagnetic squeeze film between conducting non-porous surfaces and studied the effect of the conductivities of surfaces on the performance of the bearing system. Sinha and Gupta [20] investigated the hydromagnetic effect on the porous squeeze films considering annular plates. Patel and Hingu [14] studied this effect for squeeze films between circular disks. Patel and Gupta [13] made use of Morgan-Cameron approximation and simplified this analysis, for the performance of hydromagnetic squeeze films between parallel plates with various geometrical shapes. Prakash and Vij [17] investigated the load carrying capacity and time height relation for squeeze films between porous plates. Several geometries such as circular, annular, elliptic, rectangular, conical and truncated conical plates were incorporated in this article. Prajapati [16] considered the performance of a hydromagnetic squeeze film between two conducting porous conical plates. Patel and Deheri [15] presented the study of magnetic fluid based squeeze film behavior between porous conical plates. Here, it was concluded that the magnetic fluid and the semi-vertical angle of the cone played key roles for improving the performance of the bearing system.

Tzeng and Saibel [23] recognized the random character of the roughness and introduced a stochastic concepts and succeeded in conducting an analysis of a two dimensional inclined slider bearing with one dimensional roughness in the 


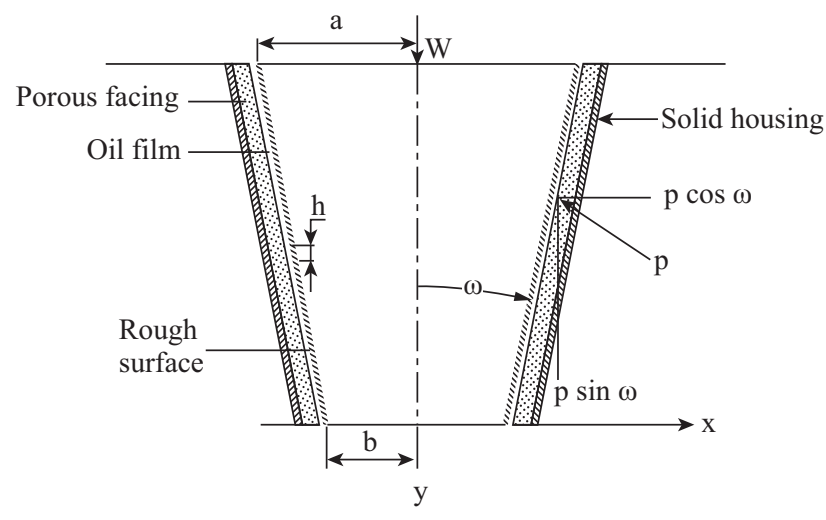

Fig. 1. Configuration of the bearing system.

direction transverse to the sliding direction. However, bearing surfaces having received some run in and wear seldom exhibit a type of roughness approximated by this model. The effect of surface roughness was studied by many investigators (Davies [6], Tonder [22], Christensen and Tonder [3-5], Berthe and Godet [2]). Christensen and Tonder [3-5] developed and modified the approach of Tzeng and Saibel [23] and proposed a comprehensive general analysis both for transverse as well as longitudinal surface roughness. Christenesen and Tonder's approach formed the basis of the analysis to study the effect of surface roughness in a number of investigations (Ting [21], Guha [9], Gupta and Deheri [10], Andharia, Gupta and Deheri [1]).

Recently, Vadher et al. [24] studied and analyzed the hydromagnetic squeeze film behavior between conducting porous transversely rough triangular plates and it was established that the negative effect introduced by the porosity and the roughness could be neutralized up to certain extent by the positive effect of hydromagnetization in the case of negatively skewed roughness. With this end in view an endeavor has been made here to investigate the behavior of a hydromagnetic squeeze film between porous conducting transversely rough truncated conical plates.

\section{ANALYSIS}

The configuration of the bearing system is given below.

The lower plate with a porous facing is assumed to be fixed, while upper plate moves along the normal towards the lower plate. The plates are considered electrically conducting and the clearance space in between is filled by an electrically conducting lubricant. An uniform transverse magnetic field is applied between the plates. The bearing surfaces are assumed to be transversely rough. The film thickness $\mathrm{h}(\mathrm{x})$ of the lubricant film is

$$
h(x)=\bar{h}(x)+h_{s}(x)
$$

where $\bar{h}(\mathrm{x})$ is the mean film thickness and $\mathrm{h}_{\mathrm{s}}(\mathrm{x})$ is the deviation from the mean film thickness characterizing the random roughness of the bearing surfaces. $h_{s}(x)$ is considered to be stochastic in nature and governed by the probability density function $\mathrm{f}\left(\mathrm{h}_{\mathrm{s}}\right)$, $-\mathrm{C} \leq \mathrm{h}_{\mathrm{s}} \leq \mathrm{C}, \mathrm{C}$ being the maximum deviation from the mean film thickness. The mean $\alpha$, the standard deviation $\sigma$ and the parameter $\varepsilon$ which is the measure of symmetry, of random variable $h_{s}$, are defined by relationships

$$
\begin{gathered}
\alpha=\mathrm{E}\left(\mathrm{h}_{\mathrm{s}}\right) \\
\sigma^{2}=\mathrm{E}\left[\left(\mathrm{h}_{\mathrm{s}}-\alpha\right)^{2}\right]
\end{gathered}
$$

and

$$
\varepsilon=\mathrm{E}\left[\left(\mathrm{h}_{\mathrm{s}}-\alpha\right)^{3}\right]
$$

where $\mathrm{E}$ denotes the expected value defined by

$$
E(R)=\int_{-C}^{C} R f\left(h_{s}\right) d h_{s}
$$

The flow in the porous medium satisfies the modified form of Darcy's law (Prajapati [16]) while in the film region the equations of hydromagnetic lubrication theory hold. Then, under the usual assumptions of hydromagnetic lubrication the modified Reynolds' equation for the lubricant film pressure (Prajapati [16], Prakash and Vij [17], Vadher et al. [24]) is obtained as

$$
\begin{aligned}
& \frac{1}{x} \frac{d}{d x}\left(x \frac{d p}{d x}\right)= \\
& \frac{\dot{\mathrm{h}}}{\left[\frac{2 \mathrm{~A}}{\mu \mathrm{M}^{3}}\left(\tanh \frac{\mathrm{M}}{2}-\frac{\mathrm{M}}{2}\right)-\frac{\psi \mathrm{A}}{\mu \mathrm{c}^{2}}\right]} \cdot \frac{1}{\left[\frac{\phi_{0}+\phi_{1}+1}{\phi_{0}+\phi_{1}+\frac{\tanh (\mathrm{M} / 2)}{(\mathrm{M} / 2)}}\right]}
\end{aligned}
$$

where

$$
\mathrm{A}=\mathrm{h}^{3}+3 \mathrm{~h}^{2} \alpha+3 \mathrm{~h}\left(\alpha^{2}+\sigma^{2}\right)+\varepsilon+3 \sigma^{2} \alpha+\alpha^{3}
$$

Solution of this equation by making use of boundary conditions

$$
\mathrm{p}(\mathrm{a} \operatorname{cosec} \omega)=0 ; \mathrm{p}(\mathrm{b} \operatorname{cosec} \omega)=0
$$

determines the non- dimensional pressure distribution as

$$
\begin{aligned}
& \mathrm{P}=\frac{-\mathrm{ph}^{3}}{\mu \dot{\mathrm{h}} \pi\left(\mathrm{a}^{2}-\mathrm{b}^{2}\right) \operatorname{cosec} \omega} \\
& =\frac{\operatorname{cosec} \omega \cdot\left[\frac{\ln (\mathrm{x} \sin \omega / \mathrm{b})}{\ln (\mathrm{a} / \mathrm{b})}-\frac{(\mathrm{x} \sin \omega / \mathrm{b})^{2}-1}{(\mathrm{a} / \mathrm{b})^{2}-1}\right]}{4 \pi\left[\frac{2 \mathrm{~B}}{\mathrm{M}^{3}}\left(\tanh \frac{\mathrm{M}}{2}-\frac{\mathrm{M}}{2}\right)-\frac{\psi \mathrm{B}}{\mathrm{c}^{2}}\right]} \cdot \frac{1}{\left[\frac{\phi_{0}+\phi_{1}+1}{\left.\phi_{0}+\phi_{1}+\frac{\tanh (\mathrm{M} / 2)}{(\mathrm{M} / 2)}\right]}\right.}
\end{aligned}
$$


wherein

$$
\mathrm{B}=1+3 \alpha^{*}+3\left(\alpha^{*^{2}}+\sigma^{*^{2}}\right)+\varepsilon^{*}+3 \sigma^{*^{2}} \alpha^{*}+\alpha^{*^{3}}
$$

Then the load carrying capacity given by

$$
\mathrm{W}=2 \pi \int_{\mathrm{b} \operatorname{cosec} \omega}^{\mathrm{a} \omega} \mathrm{posec} \omega \cdot \mathrm{xdx}
$$

is expressed in dimensionless form as

$$
\begin{aligned}
\mathrm{W}= & -\frac{\mathrm{wh}^{3}}{\mu \dot{\mathrm{h}} \pi^{2}\left(\mathrm{a}^{2}-\mathrm{b}^{2}\right)^{2} \operatorname{cosec}^{2} \omega} \\
& =\frac{\operatorname{cosec}{ }^{2} \omega \cdot\left[\frac{(\mathrm{a} / \mathrm{b})^{2}+1}{(\mathrm{a} / \mathrm{b})^{2}-1}-\frac{1}{\ln (\mathrm{a} / \mathrm{b})}\right]}{8 \pi\left[\frac{2 \mathrm{~B}}{\mathrm{M}^{3}}\left(\tanh \frac{\mathrm{M}}{2}-\frac{\mathrm{M}}{2}\right)-\frac{\psi \mathrm{B}}{\mathrm{c}^{2}}\right]} \cdot \frac{1}{\left[\frac{\phi_{0}+\phi_{1}+1}{\phi_{0}+\phi_{1}+\frac{\tanh (\mathrm{M} / 2)}{(\mathrm{M} / 2)}}\right]}
\end{aligned}
$$

Finally, if the time taken by the plate to move from the film thickness $\mathrm{h}=\mathrm{h}_{0}$ to $\mathrm{h}=\mathrm{h}_{1}$ is $\Delta \mathrm{t}$, then the dimensionless squeeze time $\Delta \mathrm{T}$ is calculated from

$$
\Delta \mathrm{T}=\int_{0}^{\mathrm{t}_{1} / \mathrm{t}_{0}} \frac{\mathrm{Wh}_{0}{ }^{2}}{\mu \pi^{2}\left(\mathrm{a}^{2}-b^{2}\right)^{2}} \mathrm{dt}
$$

which means

$$
\Delta \mathrm{T}=\frac{1}{8 \pi} \mathrm{I}
$$

where I is given by

$$
\begin{aligned}
\mathrm{I}= & -\mathrm{h}_{0}{ }^{2} \cdot \int_{1}^{\mathrm{h}_{1} / \mathrm{h}_{0}} \frac{1}{\left[\frac{2 \mathrm{~A}}{\mathrm{M}^{3}}\left(\tanh \frac{\mathrm{M}}{2}-\frac{\mathrm{M}}{2}\right)-\frac{\mathrm{KH}}{\mathrm{c}^{2}}\right]} \\
& \frac{1}{\left[\frac{\phi_{0}+\phi_{1}+1}{\left.\phi_{0}+\phi_{1}+\frac{\tanh (\mathrm{M} / 2)}{(\mathrm{M} / 2)}\right]^{\mathrm{th}}}\right.}
\end{aligned}
$$

\section{RESULTS AND DISCUSSION}

It is clearly seen that the pressure distribution is determined by Eq. (3) while Eq. (4) gives the expression for load carrying capacity. The response time is governed by Eq. (5). These performance characteristics depend on various parameters such as $\mathrm{M}, \phi_{0}+\phi_{1}, \psi, \sigma^{*}, \alpha^{*}, \varepsilon^{*}, \mathrm{k}$ and $\omega$. These parameters respectively, describe the effect of magnetization, conductivity, porosity, standard deviation, variance, skewness, aspect ratio and semi-vertical angle of the cone. Setting the roughness parameters, magnetization parameter and the conductivity parameters to be zero this study reduces to the observation of Prakash and Vij [17]. Further taking $\psi=0$ this investigation tends to the performance of a squeeze film between nonporous truncated conical plates. Lastly, considering the roughness parameters to be zero the present study results in the contributions of Shukla and Prasad [19], Dodge et al. [7] and Sinha and Gupta [20] under special situations.

It can be easily noticed that the load carrying capacity increases for fixed values of $\mathrm{M}, \psi, \sigma^{*}, \alpha^{*}, \varepsilon^{*}, \mathrm{k}$ and $\omega$ as the conductivity parameter $\phi_{0}+\phi_{1}$ increases. Moreover, the effect of conductivity on the pressure distribution, load carrying capacity and response time comes through the factor

$$
\left(\frac{\phi_{0}+\phi_{1}+\frac{\tanh (\mathrm{M} / 2)}{(\mathrm{M} / 2)}}{\phi_{0}+\phi_{1}+1}\right)
$$

This tends to $\frac{\phi_{0}+\phi_{1}}{\phi_{0}+\phi_{1}+1}$ as tanhM $\sim 1,2 / \mathrm{M} \sim 0$ for large values of M. It is obvious that both of these functions are increasing functions of $\phi_{0}+\phi_{1}$. It may be observed from mathematical analysis also that as $\phi_{0}+\phi_{1}$ increases; the pressure, load carrying capacity and response time increase. An interesting point to be noted here is that the bearing with magnetic field can support a load even when there is no flow.

In Figs. 2-8 the variation of load carrying capacity with respect to the magnetization parameter is presented for various values of porosity parameter $\psi$, conductivity parameter $\phi_{0}+$ $\phi_{1}$, standard deviation $\sigma^{*}$, variance $\alpha^{*}$, skewness $\varepsilon^{*}$, aspect ratio $\mathrm{k}$ and semi-vertical angle $\omega$ respectively. It is clearly seen from these figures that the load carrying capacity increases substantially with respect to the magnetization parameter wherein the effect of (-ve) $\alpha^{*}$ is most the predominant, followed by semi-vertical angle $\omega$. Further, initially the standard deviation has an almost negligible effect and the increase in load carrying capacity for the combination of $M$ and $\sigma^{*}$ is relatively less as compared to the other cases. Besides, the effect of standard deviation is quite adverse.

Figs. 9-14 depict the distribution of load carrying capacity with respect to the conductivity $\phi_{0}+\phi_{1}$ for several values of the parameters $\psi, \sigma^{*}, \varepsilon^{*}, \alpha^{*}, \mathrm{k}$ and $\omega$ respectively. It is observed that the conductivity tends to increase the load carrying capacity and the rate of increase at the initial stages is relatively more. Here, the combined effect of the conductivity and aspect ratio is relatively better than the combined effect of conductivities and porosity while the combined effect of negative $\varepsilon^{*}$ and conductivity $\phi_{0}+\phi_{1}$ is comparatively less than the combined effect of negative $\alpha^{*}$ and conductivity $\phi_{0}+\phi_{1}$. Further, it is noted that the combined effect of conductivity and the aspect ratio lies between the effect of negative variance 


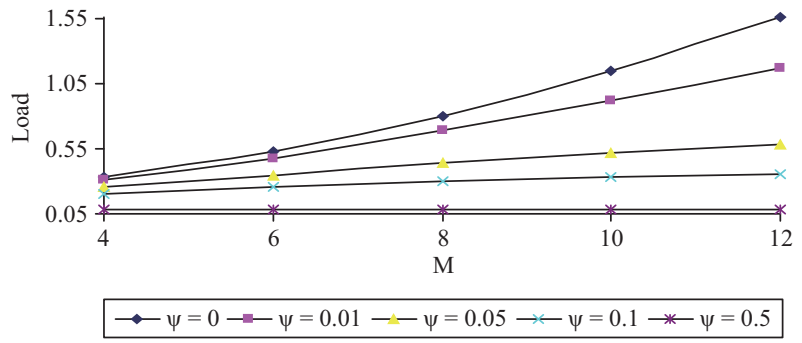

Fig. 2. Variation of load carrying capacity with respect to $M$ and $\psi$.

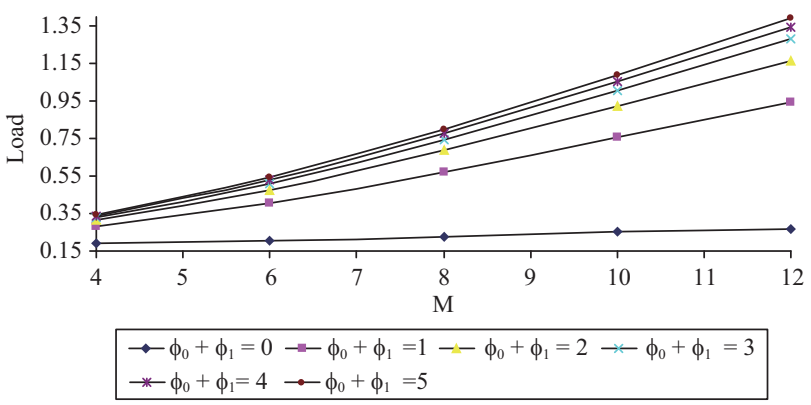

Fig. 3. Variation of load carrying capacity with respect to $M$ and $\phi_{1}+\phi_{0}$.

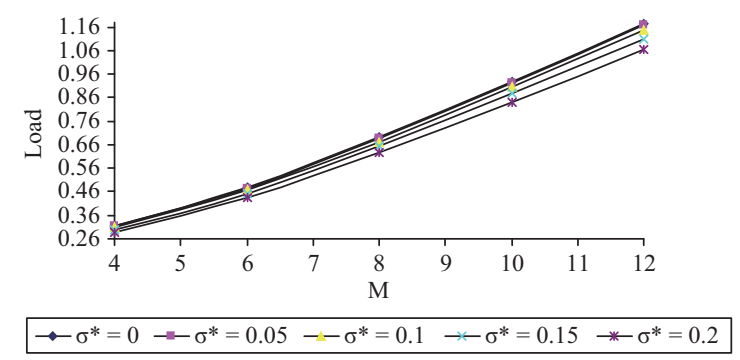

Fig. 4. Variation of load carrying capacity with respect to $M$ and $\sigma^{*}$.

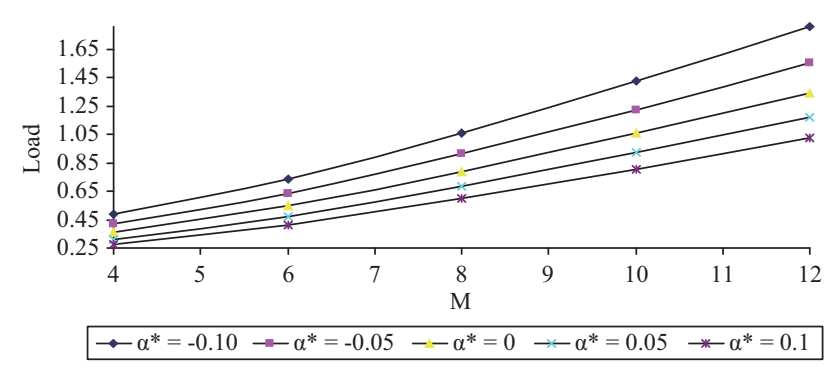

Fig. 5. Variation of load carrying capacity with respect to $M$ and $\alpha^{*}$.

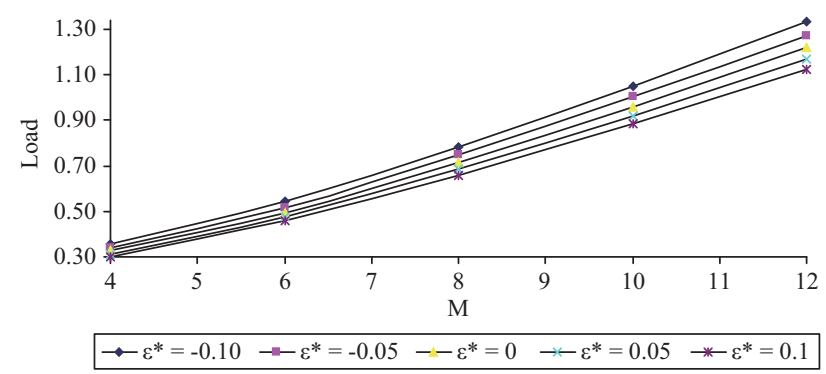

Fig. 6. Variation of load carrying capacity with respect to $M$ and $\varepsilon^{*}$.

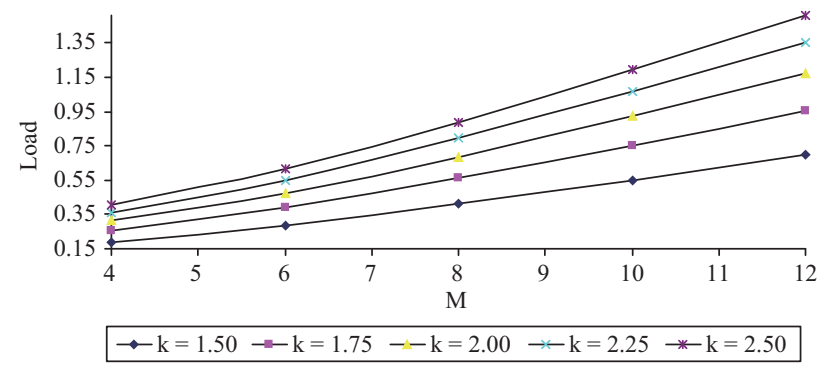

Fig. 7. Variation of load carrying capacity with respect to $M$ and $k$.

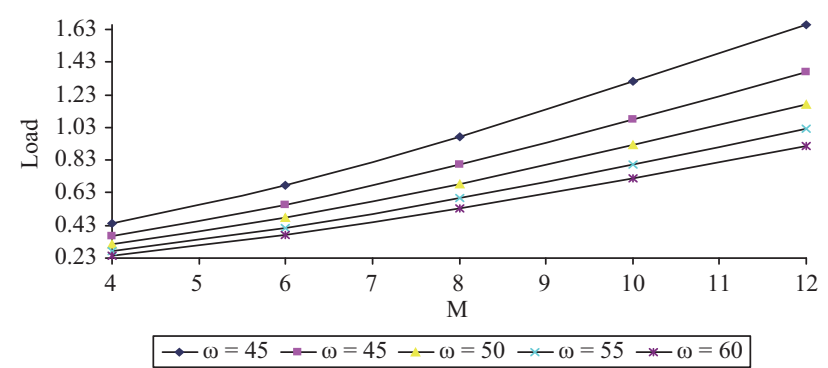

Fig. 8. Variation of load carrying capacity with respect to $M$ and $\omega$.

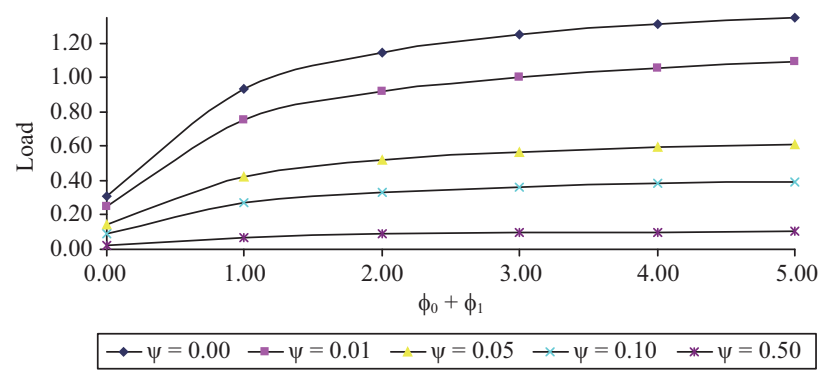

Fig. 9. Variation of load carrying capacity with respect to $\phi_{0}+\phi_{1}$ and $\psi$.

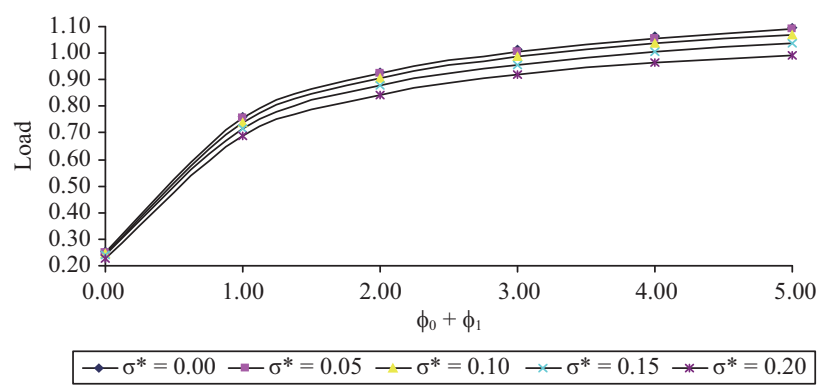

Fig. 10. Variation of load carrying capacity with respect to $\phi_{0}+\phi_{1}$ and $\sigma^{*}$.

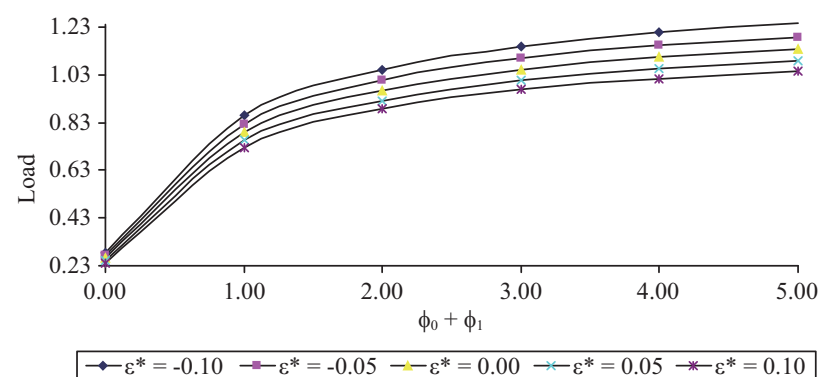

Fig. 11. Variation of load carrying capacity with respect to $\phi_{0}+\phi_{1}$ and $\varepsilon^{*}$. 


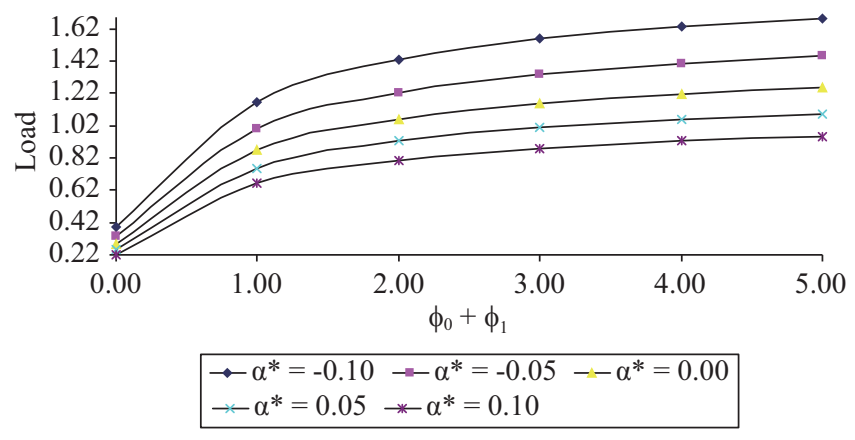

Fig. 12. Variation of load carrying capacity with respect to $\phi_{0}+\phi_{1}$ and $\alpha^{*}$.

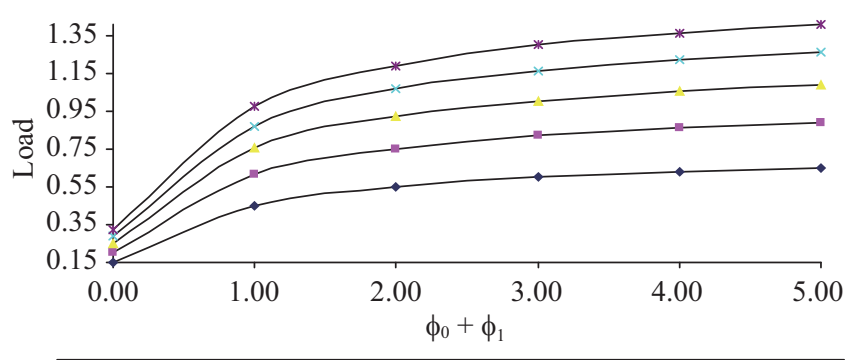

$\rightarrow-\mathrm{k}=1.50 \rightarrow-\mathrm{k}=1.75 \quad--\mathrm{k}=2.00 \rightarrow-\mathrm{k}=2.25 \rightarrow-\mathrm{k}=2.50$

Fig. 13. Variation of load carrying capacity with respect to $\phi_{0}+\phi_{1}$ and $k$.

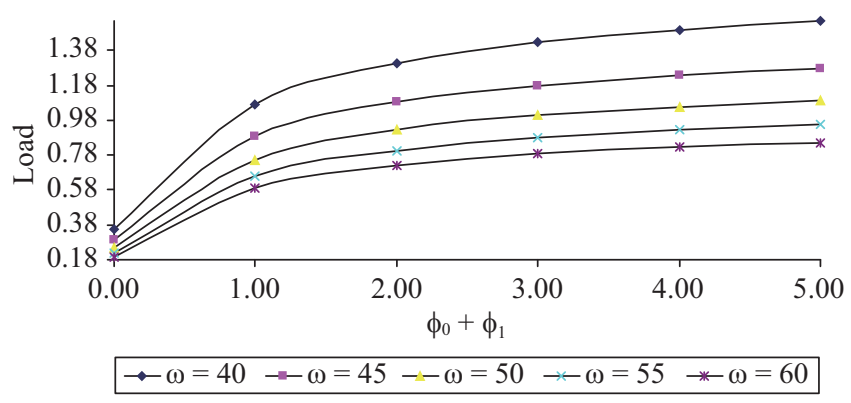

Fig. 14. Variation of load carrying capacity with respect to $\phi_{0}+\phi_{1}$ and $\omega$.

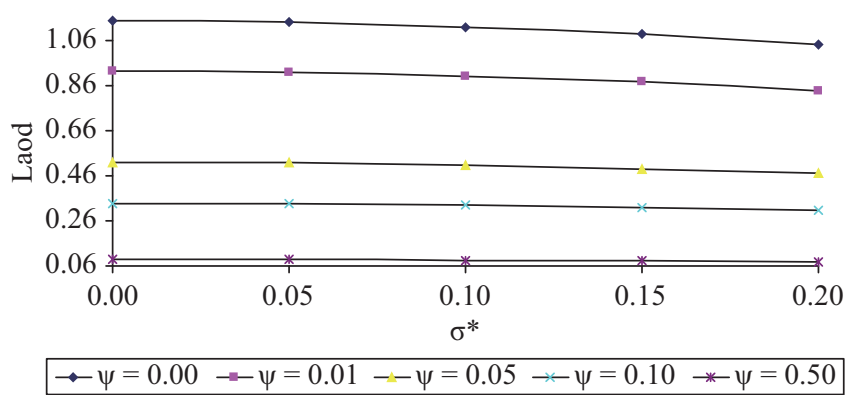

Fig. 15. Variation of load carrying capacity with respect to $\sigma^{*}$ and $\psi$.

and skewness so far as the increase in load carrying capacity is concerned.

We have the effect of porosity on the distribution of load carrying capacity in Figs. 15-19 for different values of $\sigma^{*}, \alpha^{*}$, $\varepsilon^{*}, \mathrm{k}$ and $\omega$ respectively. These figures indicate that porosity has a considerable adverse effect on the performance of the bearing system. It is also clearly visible that the decrease in

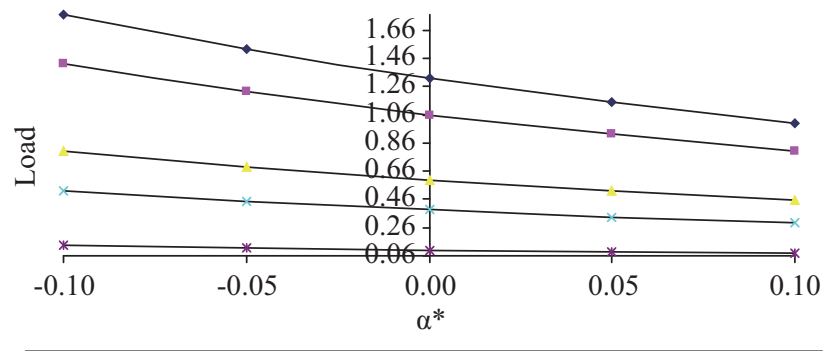

$\rightarrow-\psi=0.00 \rightarrow-\psi=0.01--\psi=0.05 \rightarrow-\psi=0.10 \rightarrow \psi \psi=0.50$

Fig. 16. Variation of load carrying capacity with respect to $\alpha^{*}$ and $\psi$.

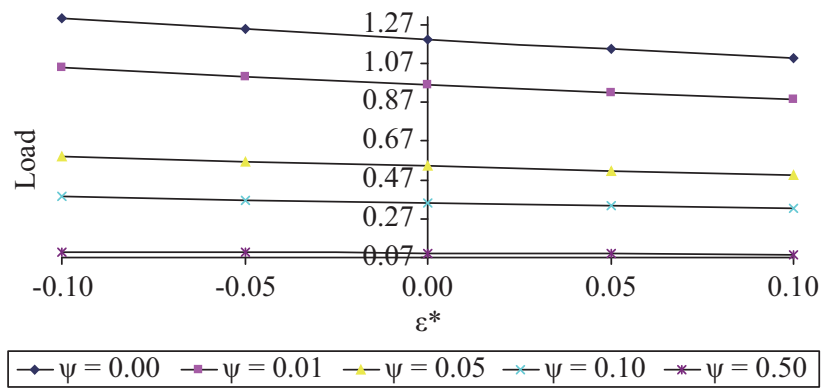

Fig. 17. Variation of load carrying capacity with respect to $\varepsilon^{*}$ and $\psi$.

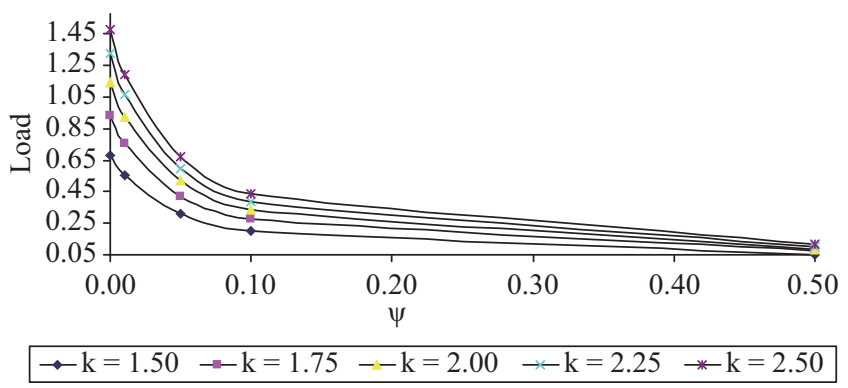

Fig. 18. Variation of load carrying capacity with respect to $\psi$ and k.

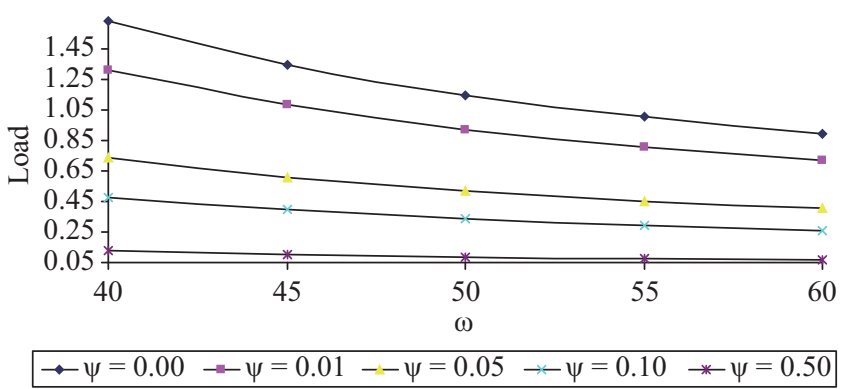

Fig. 19. Variation of load carrying capacity with respect to $\omega$ and $\psi$.

load carrying capacity is considerably more at the initial stage up to the value of $\psi \sim 0.25$ and the effect of porosity with respect to standard deviation is almost negligible which can be seen from Fig. 15. These figures make it clear that the bearing suffers on account of porosity. Besides, the negative effect of porosity can be compensated by the positive effect of negatively skewed roughness and this compensation is relatively more in the case of negative variance. 


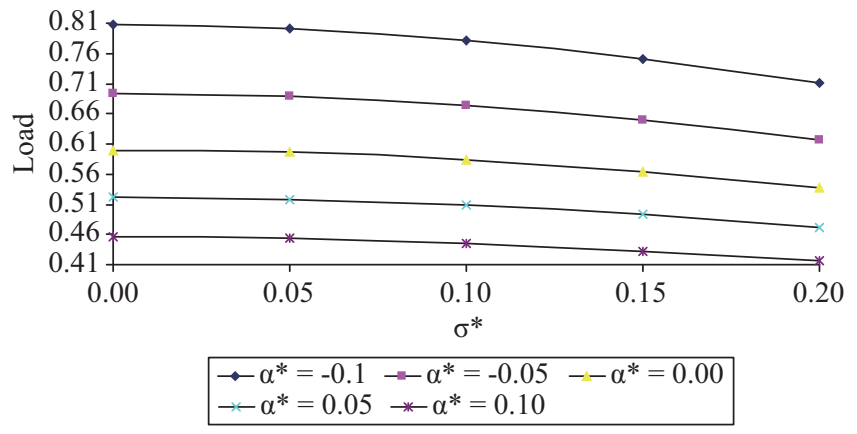

Fig. 20. Variation of load carrying capacity with respect to $\sigma^{*}$ and $\alpha^{*}$.

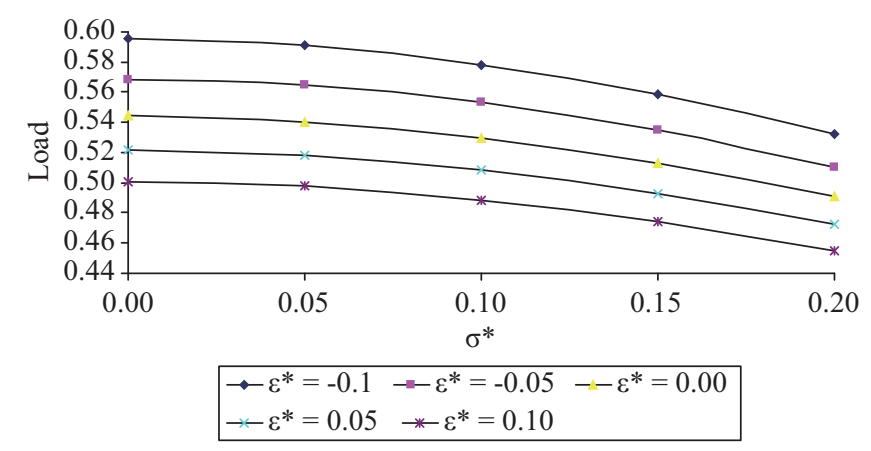

Fig. 21. Variation of load carrying capacity with respect to $\sigma^{*}$ and $\varepsilon^{*}$.

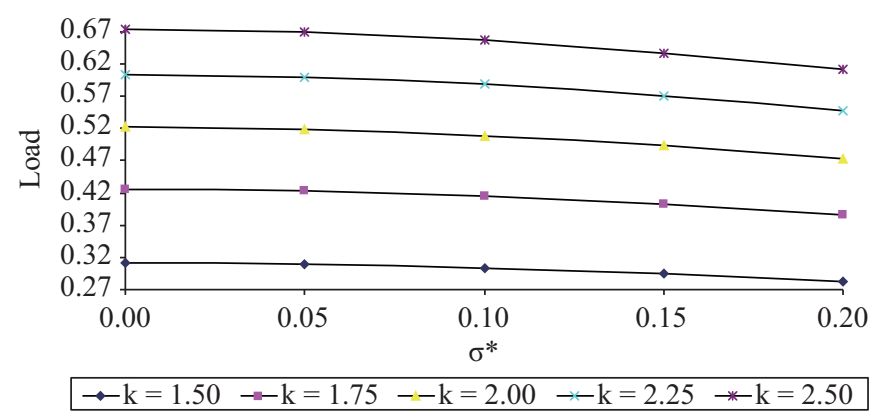

Fig. 22. Variation of load carrying capacity with respect to $\sigma^{*}$ and $k$.

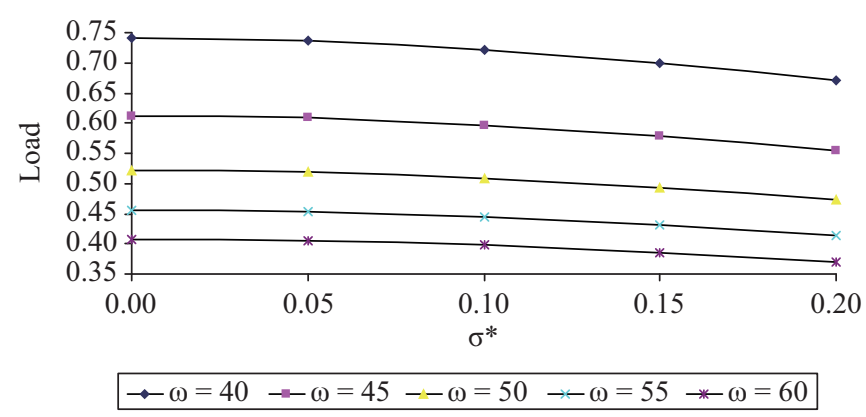

Fig. 23. Variation of load carrying capacity with respect to $\sigma^{*}$ and $\omega$.

Figs. 20-23 give the profile for the distribution of load carrying capacity with respect to the standard deviation associated with roughness for various values of variance, skewness, aspect ratio and the semi-vertical angle respectively. These figures make it clear that the effect of standard deviation is

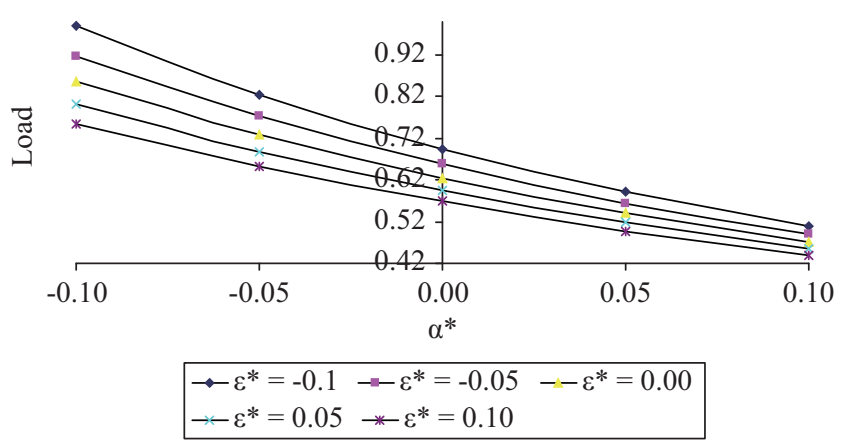

Fig. 24. Variation of load carrying capacity with respect to $\alpha^{*}$ and $\varepsilon^{*}$.

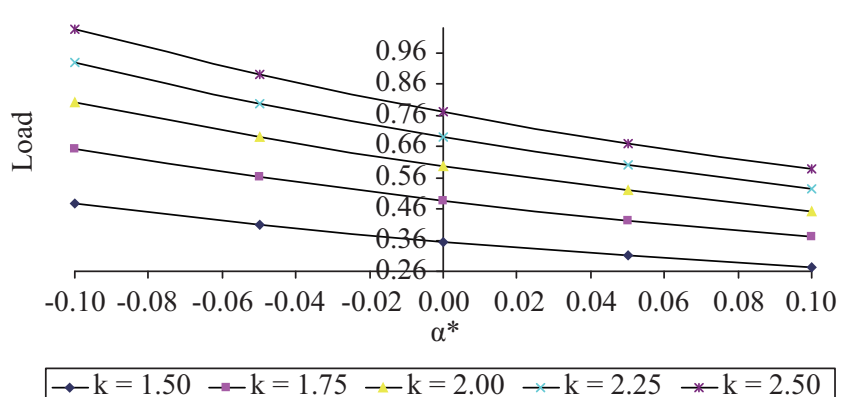

Fig. 25. Variation of load carrying capacity with respect to $\alpha^{*}$ and $k$.

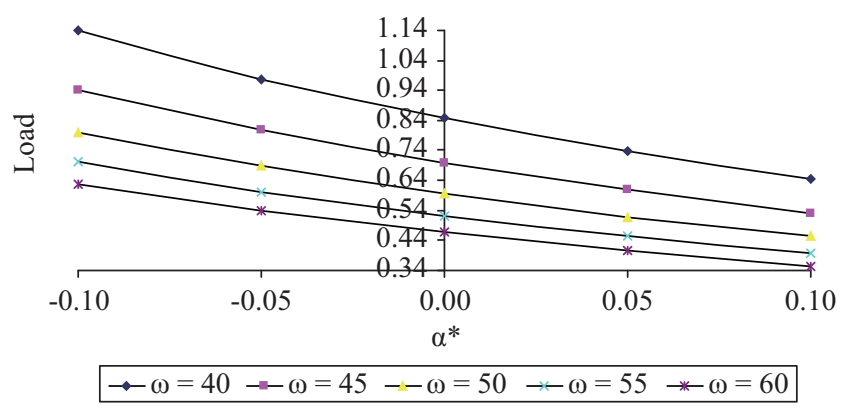

Fig. 26. Variation of load carrying capacity with respect to $\alpha^{*}$ and $\omega$.

considerably adverse although, at the initial stage the decrease is marginal. The rate of decrease is more pronounced in the case of skewness. Variation of load carrying capacity with respect to the variance for different values of skewness, aspect ratio and the semi vertical angle is presented in Figs. 24-26 respectively. While $\alpha^{*}(+\mathrm{ve})$ decreases the load carrying capacity, the (-ve) variance increases the load carrying capacity and this rate of increase is more in the case of the aspect ratio. The effect of the measure of symmetry for various values of aspect ratio and the semi-vertical angle is shown in Figs. 27 and 28. While skewness (+ve) decreases the load carrying capacity the load carrying capacity increases due to negatively skewed roughness. The effect of the combination $\varepsilon^{*}$ and $\omega$ is relatively better than that of $\varepsilon^{*}$ and $\mathrm{k}$. Finally, the effect of $\mathrm{k}$ and $\omega$ is given in Fig. 29, which makes it clear that the effect of the aspect ratio is significantly positive, while the load carrying capacity decreases with increasing values of the semi-vertical angle. 


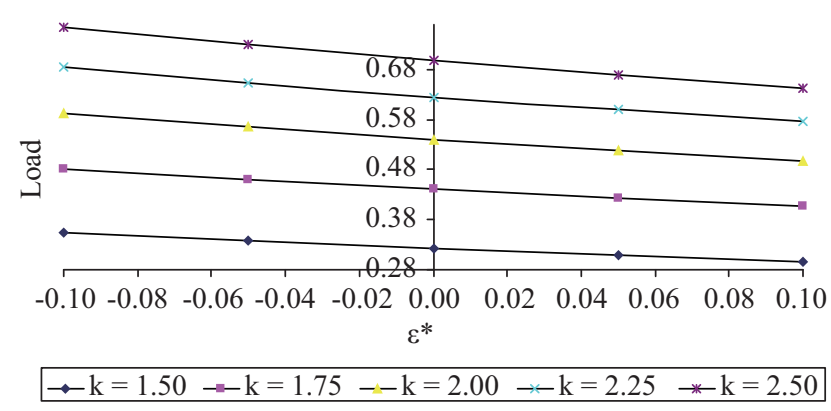

Fig. 27. Variation of load carrying capacity with respect to $\varepsilon^{*}$ and $\mathbf{k}$.

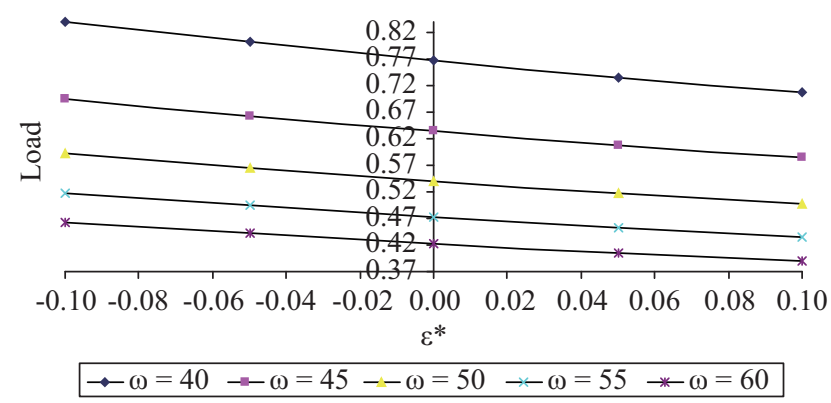

Fig. 28. Variation of load carrying capacity with respect to $\varepsilon^{*}$ and $\omega$.

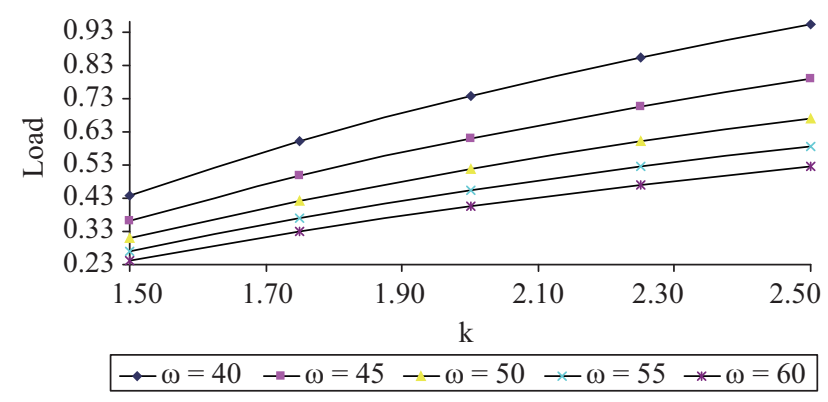

Fig. 29. Variation of load carrying capacity with respect to $k$ and $\omega$.

The response time follows the trends of load carrying capacity as can be seen from mathematical expression (5). Moreover, this article suggests that the combined effect of magnetization parameter and aspect ratio prevents the response time to fall rapidly in the case of negatively skewed roughness especially, when negative variance occurs.

This study establishes that the negative effect of porosity, standard deviation, and semi-vertical angle can be compensated up to a considerable extent by the positive effect induced by the magnetization parameter, conductivity and the aspect ratio in the presence of negatively skewed roughness. Further, this compensation is relatively more when negative variance is involved. Thus, for a better performance of hydromagnetic squeeze film the radii ratio and the conductivities must be given priority while designing the bearing system in the case of negatively skewed roughness even if, the semi-vertical angle is chosen suitably. Besides, the roughness must be accounted for while designing the bearing system.

\section{CONCLUSION}

The practical importance of the present study lies in understanding the bearing's behavior during steady state performance and also transient squeezing period. A comparison with the earlier studies indicates that there is at least $8 \%$ increase in the load carrying capacity in spite of the fact that the transverse surface roughness affects the bearing system adversely. This article offers sufficient scopes for improving the performance of the bearing system by providing an additional degree of freedom. Besides, this investigation makes it mandatory that the roughness must be given due consideration while designing the bearing system because even the negative variance increase the load carrying capacity.

\section{NOMENCLATURE}
a, b
Radii (a $>$ b) (m)
$\mathrm{B}_{0} \quad$ Uniform transverse magnetic field applied between the plates
$=1+\frac{\mathrm{KM}^{2}}{\mathrm{~h}^{2} \mathrm{~m}}$
$\mathrm{H}$
Lubricant film thickness (m)
$\mathrm{H} \quad$ Magnetic field component (gauss)
$\mathrm{H}_{0} \quad$ Thickness of the porous wall (m)
$\mathrm{h}_{0}^{\prime} \quad$ Surface width of the lower plate $(\mathrm{m})$
$h_{1}^{\prime} \quad$ Surface width of the upper plate (m)
$\mathrm{K} \quad$ Aspect ratio (a/b)
$\mathrm{K} \quad$ Permeability $\left(\mathrm{col}^{2} \mathrm{kgm} / \mathrm{s}^{2}\right.$ )
$\mathrm{M} \quad$ Porosity of the porous matrix

M

$=\mathrm{B}_{0} \mathrm{~h}\left(\frac{\mathrm{s}}{\mu}\right)^{1 / 2}=$ Hartmann number

Pressure distribution $\left(\mathrm{N} / \mathrm{m}^{2}\right)$

$\mathrm{P}$

$P$

Non-dimensional pressure

Electrical conductivity of the lubricant (mho)

Electrical conductivity of lower surface (mho)

Electrical conductivity of upper surface (mho)

Load carrying capacity $\left(\mathrm{kgm} / \mathrm{s}^{2}\right)$

Dimensionless load carrying capacity

Response time (s)

Non-dimensional response time

$\Delta \mathrm{T}$

$\phi_{0}(\mathrm{~h})$

$=\frac{\mathrm{s}_{0} \mathrm{~h}_{0}^{\prime}}{\mathrm{sh}}$

$\begin{array}{ll}\phi_{1}(\mathrm{~h}) & =\frac{\mathrm{s}_{1} \mathrm{~h}_{1}^{\prime}}{\mathrm{sh}} \\ \psi & =\frac{\mathrm{KH}_{0}}{\mathrm{~h}^{3}}\end{array}$

Viscosity $(\mathrm{kg} / \mathrm{ms})$

Magnetic susceptibility $\left(\mathrm{m}^{3} / \mathrm{kg}\right)$

Permeability of the free space $\left(\mathrm{N} / \mathrm{A}^{2}\right)$

Semi-vertical angle of the cone $\left(^{\circ}\right)$

Non-dimensional standard deviation $(\sigma / \mathrm{h})$ 
$\alpha^{*} \quad$ Non-dimensional variance $(\alpha / \mathrm{h})$

$\varepsilon^{*} \quad$ Non-dimensional skew ness $\left(\varepsilon / \mathrm{h}^{3}\right)$

\section{ACKNOWLEDGMENTS}

Authors place on record sincere thanks to the referees for their constructive suggestions, and comments towards the presentation of the paper in a fruitful way.

Two of the authors, R. M. Patel and G. M. Deheri thank UGC for the funding of U. G. C. major research project (U. G. C. F. No. 32-143/2006 (SR) - "Magnetic fluid based rough bearings") under which this study has been carried out.

\section{REFERENCES}

1. Andharia, P. I., Gupta, J. L., and Deheri, G. M., "Effect of transverse surface roughness on the behaviour of squeeze film in a spherical bearing," Journal of Applied Mechanics and Engineering, Vol. 4, pp. 19-24 (1999).

2. Berthe, D. and Godet, M., "A more general form of Reynolds equation Application to rough surfaces," Wear, Vol. 27, pp. 345-357 (1973).

3. Christensen, H. and Tonder, K. C., "Tribology of rough surfaces: Parametric study and comparison of lubrication models," SINTEF Report No. 22/69-18 (1969).

4. Christensen, H. and Tonder, K. C., "Tribology of rough surfaces: Stochastic models of hydrodynamic lubrication," SINTEF Report No. 10/69-1 (1969).

5. Christensen, H. and Tonder, K. C., "Tribology of rough surfaces: A stochastic model of mixed lubrication," SINTEF Report No. 18/70-21 (1970).

6. Davis, M. G., "The generation of pressure between rough lubricated, moving deformable surfaces," Lubrication Engineering, Vol. 19, pp. 246252 (1963)

7. Dodge, F. T., Osterle, J. F., and Rouleau, W. T., "Magnetohydrodynamic squeeze film bearings," Journal of Basic Engineering Transaction, ASME, Vol. 87, pp. 805-809 (1965).

8. Elco, R. A. and Huges, W. F., "Magnetohydrodynamic pressurization in liquid metal lubrication," Wear, Vol. 5, pp. 198-212 (1962).

9. Guha, S. K., "Analysis of dynamic characteristics of hydrodynamic jour- nal bearings with isotropic roughness effects," Wear, Vol. 167, pp. 173 179 (1993).

10. Gupta, J. L. and Deheri, G. M., "Effect of roughness on the behaviour of squeeze film in a spherical bearing," Tribology Transactions, Vol. 39, pp. 99-102 (1996).

11. Kuzma, D. C., "Magnetohydrodynamic squeeze films," Journal of Basic Engineering Transaction, ASME, Vol. 86, pp. 441-444 (1964).

12. Kuzma, D. C., Maki, E. R., and Donnelly, R. J., "The magnetohydrodynamic squeeze films," Journal of Fluid Mechanics, Vol. 19, pp. 395-400 (1964).

13. Patel, K. C. and Gupta, J. L., "Behavior of hydromagnetic squeeze film between porous plates," Wear, Vol. 56, pp. 327-339 (1979).

14. Patel, K. C. and Hingu, J. V., "Hydromagnetic squeeze film behavior in porous circular disks," Wear, Vol. 49, pp. 239-246 (1978).

15. Patel, R. M. and Deheri, G. M., "Magnetic fluid based squeeze film between porous conical plates," Industrial Lubrication and Tribology, Vol. 59, No. 3, pp. 143-147 (2007).

16. Prajapati, B. L., On Certain Theoretical Studies in Hydrodynamic and Electromagnetohydrodynamic Lubrication, Ph.D. Thesis, Sardar Patel University, Vallabh Vidyanagar, Gujarat, India (1995).

17. Prakash, J. and Vij, S. K., "Load capacity and time height relations for squeeze film between porous plates," Wear, Vol. 24, pp. 309-322 (1973).

18. Shukla, J. B., "Hydromagnetic theory of squeeze films," ASME, Vol. 87, pp. 142-144 (1965).

19. Shukla, J. B. and Prasad, R., "Hydromagnetic squeeze films between two conducting surfaces," Journal of Basic Engineering Transaction, ASME, Vol. 87, pp. 818-823 (1965).

20. Sinha, P. C. and Gupta, J. L., "Hydromagnetic squeeze films between porous annular disks," Journal of Mathematical and Physical Sciences, Vol. 8, pp. 413-422 (1974).

21. Ting, L. L., "Engagement behaviour of lubricated porous annular disks Part I: Squeeze film phase, surface roughness and elastic deformation effects," Wear, Vol. 34, pp. 159-172 (1975).

22. Tonder, K. C., "Surface distributed waviness and roughness," First World Conference in Industrial Tribology, New Delhi, Vol. A3, p. 128 (1972).

23. Tzeng, S. T. and Saibel, E., "Surface roughness effect on slider bearing lubrication," Journal of Lubrication Technology Transaction, ASME, Vol. 10, pp. 334-348 (1967).

21. Vadher, P. A., Deheri, G. M., and Patel, R. M., "Hydromagnetic squeeze film between conducting porous transversely rough triangular plates," Annals of Faculty of Engineering Hunedoara, Vol. 6, pp. 155-168 (2008). 